\title{
A qualitative study of compliance with medication and lifestyle modification in Chronic Obstructive Pulmonary Disease (COPD)
}

\author{
R.C.M. Jones*, Michael E. Hyland, Karen Hanney, Jo Erwin
}

\author{
Respiratory Research Unit, Peninsula Medical School, Room N11, ITTC Building, \\ Tamar Science Park, 1 Davy Road, Plymouth PL6 8BX, UK
}

Received 12 December 2003; accepted 17 May 2004

KEYWORDS
Compliance;
Concordance;
Chronic Obstructive
Pulmonary Disease;
COPD;
Focus group;
Lifestyle

Introduction

The treatment of chronic obstructive pulmonary disease has many similarities with asthma, so it is

\footnotetext{
${ }^{*}$ Corresponding author. Tel.: +44 1752 764293; fax: +44 1752764230 .

E-mail address: rupert.jones@pms.ac.uk (R.C.M. Jones).
} their disease effectively.
Summary Aim: The aim of this study is to examine patients' perceptions of factors that influence their compliance with inhaled therapy for COPD, and their compliance with health related behaviours related to smoking cessation, exercise and diet.

Methods: Five focus groups of 29 diagnosed COPD patients who had not attended pulmonary rehabilitation were recruited from secondary and primary care. The severity of their illness ranged from mild to severe. For each group, the moderator asked patients what they had been told and what they actually did with regard to medication, smoking, exercise and diet.

Results: All patients except one reported good compliance with medication but some patients expressed concerns about technique. All patients reported being told to stop smoking, but patients varied as to whether they believed that smoking was harmful or not. Some had stopped smoking, some had tried to cut down, and others continued as normal. Patients had not been offered constructive help to quit smoking. Patients had been told to exercise but were given inadequate information as to why this was helpful. Patients were unsure how much they should exercise, and were unsure whether breathlessness during exercise was harmful. Patients had been given minimal advice about diet.

Conclusions: Patients with COPD have low levels of intentional non-compliance with medication in COPD, probably because, unlike asthmatics, these patients are chronically symptomatic. Fear of dyspnoea and feelings of vulnerability also appear to contribute to good compliance. Information given by health professionals about lifestyle modification was poor. COPD patients require better education to manage

๑ 2004 GeneralPractice Airways Group. Püblished by Elsevier Ltd. All rights reserved. reasonable to assume that there are similarities in the way patients with these diagnoses adhere to their drug regime. Compliance with inhaled medication in asthmatics is known to be poor with $40-50 \%$ of patients undermedicating with respect to current guidelines for optimum disease control [1-7]. The limited available data suggests that compliance with inhaled medication in COPD pa- 
tients is better than that of asthmatics [8]. Qualitative studies show that intentional undermedication in asthmatics is motivated by a dislike or anxiety about continuous use of steroids, and the belief that it is possible to develop a tolerance to the effects of the drugs [9]. Little is known about intentional non-compliance with inhaled medication in COPD.

In COPD, fear of dyspnoea reduces the desire to exercise. The subsequent physical deconditioning and demotivation combine to create a spiral of decline. The treatment for COPD encompasses medication and lifestyle change; this can be a considerable task for some patients. Treatment should include advice on smoking cessation, exercise, diet and (importantly) coping strategies for daily symptoms and for exacerbations. Compliance with lifestyle advice is critical in COPD, and smoking cessation is essential to reduce the rate of decline of lung function [10]. Apprising patients of the reasons for engaging in these changes plus the resources and support to encourage them is essential. A validated pulmonary rehabilitation (PR) course should address these issues [11].

To determine compliance with prescribed medication by subjective reporting has its advantages and disadvantages. However, the similarity in findings between electronic recording and subjective reporting in asthma suggests that subjective reporting is a valid method of assessing compliance [12]. The advantage of subjective reporting is that patients can describe strategies of medication use during episodes of deterioration or improvement. In the case of COPD, they can also describe to what extent they have engaged in lifestyle modifications. The aim of this study was to use subjective reporting to examine the issues for patients concerning compliance with treatment for COPD.

\section{Methods}

Five focus groups of twelve people were recruited; three from primary care and two from secondary care via the chest clinic. The criteria used for recruitment are as follows:

Patients were included if they:

- Had a COPD diagnosis according to BTS criteria [13] with spirometry repeated if not performed in the last 12 months

- Were more than 40 years old

Patients were excluded if they:

- Had asthma
- Had undergone pulmonary rehabilitation courses

- Were unable to give informed consent or were unsuitable for inclusion in focus groups

- Had substantial, significant co-existing morbidity from another disease, and were likely to become severely ill in the near future

- Had a serious exacerbation of their COPD in the four weeks prior to recruitment

- Were involved in other research project.

Selection of focus group participants:

The participants in each focus group were selected to reflect a range of the total study population with an aim of achieving heterogeneity in each group. Each group had:

- At least two males and two females

- At least two moderate and two severe COPD patients

- At least two current smokers and two ex-smokers

This design allowed for an exploration of different perspectives within each group.

Focus group setting and procedure

The focus groups were arranged at local hotels; participants' travel expenses were reimbursed. Where necessary a carer or relative accompanied the patients. The moderator $(\mathrm{MH})$ explained that the purpose of the research was to gain a better understanding of how they as patients had been treated and what advice they had been given about their COPD. The sessions lasted for approximately one hour.

Topics of discussion were:

- The name and nature of the disease

- Understanding of inhaled drug therapy, compliance with directions for inhaled medication

- Access to urgent medical care

- Tobacco smoking behaviour, smoking-related beliefs, and smoking-cessation information given

- Exercise behaviour, exercise-retated beliefs and exercise-related information given

- Dietary information given

- Any other areas of interest or concern to patients

The focus groups were recorded on audiotape with the consent of the subjects, and hand-written notes were taken by the moderator during the session. The notes were reviewed and the audiotapes were listened to repeatedly. The data was analysed using thematic content analysis, with emerging themes logged until saturation occurred and no new themes emerged. The themes were coded and split further into sub-categories where appropriate. 


\section{Results}

Sixty-three patients were invited to take part in the study. Thirty-four patients $(47 \%$ male and $53 \%$ female) refused or were too ill to participate. Hence, the sample consisted of 29 patients, 20 male and 9 female. The mean age was 67 with a range of 51-79 years. The smoking characteristics were 8 current smokers, 5 recent ex-smokers and 16 non-smokers ('never smoked' or 'given up for more than one year'). The classification of COPD severity according to BTS criteria was five mild, twelve moderate and twelve severe.

\section{The name and nature of their chest disease}

The majority of patients understood that their disease involved their lungs. However, few had been given the name Chronic Obstructive Pulmonary Disease (COPD) to describe their condition.

"I couldn't tell you [what the disease is called] because I haven't been told. I've just been given medicine and tablets and told to stay in.",

Some patients who had been given two names for their disease, for example the names 'COPD' and 'emphysema', were confused as to which one they had. Those that had not been given a name for their disease felt that a lack of disease label was unsatisfactory. There was a universal understanding that their disease was serious and unlikely to improve.

\section{Understanding of inhaled drug therapy and compliance with directions for inhaled medication}

The majority of patients or their carers had a good understanding of their inhalers and were clear about the importance of taking them regularly. They understood which medicines were for regular use and those to be used on an 'as needed' basis, and were clear about frequency of use. Many patients lacked information on minor points of correct usage e.g. rinsing the mouth after use and using a spacing device. Some patients felt that the instructions for inhaler/spacer usewere inconsistent between health professionals.

"But as to how to take them every doctor seems to tell you something different actually. One doctor said take a puff and carry on breathing, another one says take a big puff and hold your breath. It's a bit of a worry."

In another example, a GP had told a patient to "use it straight"' after the hospital consultant had given them a spacer. It was generally felt that a change to a new inhaler improved their symptoms, but many felt unsure of their inhaler technique especially during an exacerbation.

There was a general feeling that inhalers could work well on one occasion and not on another, and that inhalers were not as effective as they would like them to be. One patient was prescribed an inhaler he perceived to be 'cheaper' than his previous one and he found it 'not so good'. Patients had a general lack of confidence in their own technique and a few had panicked during an exacerbation so their breathing technique was wrong. There was difficulty judging when their inhalers were empty, which increased anxiety about the effectiveness of the inhalers during an exacerbation.

Most patients reported good compliance with their inhaled therapy and rarely forgot to take their inhalers.

"No I don't forget [to use inhaler]. It's a regimen in my house. Anything to help you breathe."

One patient reported that he was "very particular about taking it" and another said, "I never forget - I have rituals, so I don't'. Another said, "you got no choice". Many had concerns about becoming 'tolerant' or 'addicted' to their drugs, and after prolonged use they would not work as well:

"Sometimes if you're taking medicine on a regular basis your system can become immune to it."

They felt that their treatment should be reviewed when this happened.

All focus group participants were asked about their use of inhalers. About a third of patients had no concerns about their inhalers and one felt that 'the more steroids the better'. Only one patient was attempting to 'ration' her use of inhalers. Those with concerns about tolerance still reported taking their medicine as instructed: one patent commented "I wouldn't dare do otherwise". The fear of dyspnoea appeared to be an important factor in compliance:

"it älways remember [to use inhaler] but I often wonder what it would be like if I ever forgot it. I would never risk it though I'm so dependent on it to breathe."

\section{What to do in an emergency}

A minority of patients were confident about their actions in an emergency. The same patients felt that they had a good relationship with their GP. "He will come out within half an hour" and "if I ring the surgery, I can always see somebody the same day". 
Many patients expressed feelings of guilt if they had to call the GP and often left the decision to a carer or family member, usually at a point too late to avoid hospital admission. Most had no written or verbal information on when to telephone 999 for an ambulance; interestingly, only one patient had a written self-management plan that contained this information and she had recently moved to the area from Kent.

\section{Tobacco smoking behaviour, smoking-related beliefs, and smoking-cessation information given by health professionals}

Many patients pointed out that smoking was not known to be harmful when they started smoking:

"I was told it was emphysema mostly through smoking. I've been a smoker all my life, but we didn't know the dangers of smoking back then."

The GP's or practice nurses had told almost all patients that smoking was the cause of their disease and that to continue to smoke was harmful. Those patients who had heeded this advice and had given up using tobacco felt that health professionals had not offered them help with the process. They had decided to quit and they had done so using willpower. The patients who continued to smoke felt that they were 'unable to stop' or that 'the damage was already done'. Not surprisingly many of these patients often claimed a cause other than smoking for their disease "I worked in the dockyard all my life". Smoking patients varied, some saying, "the doctor knows I still have the odd smoke," whereas others appeared unconvinced that smoking was really that bad.

There were many feelings of guilt and blame associated with smoking:

"As for me l've only got myself to blame because I was a smoker for 50 years. So I've got no axe to grind. It was my own fault."

"If you mention to a doctor when you're in hospital that you've been a smoker they seem to think 'Oh well you got what you deserve' sort of thing."

\section{Exercise behaviour, exercise-related beliefs and exercise-related information given by health professionals}

Most patients had been told that it was 'good' to exercise; however, it was thought to be 'not enough information' by almost all patients.
"Nobody has actually told me whether it is good or not to get out of breath when taking exercise. I would have thought that was something very basic that they need to explain."'

It was suggested to one patient to 'take up singing to open his lungs', another to 'start swimming regularly' for the same reason. There was a misunderstanding of the word 'exercise' as some felt that it meant to take strenuous exercise i.e. keep fit class. They felt that this was beyond their physical capabilities, but almost all tried to keep active in the garden or by walking regularly, but most had 'no idea' about how much exercise to do. Getting out of breath was 'frightening' and 'embarrassing', so often they avoided becoming breathless by walking a lesser distance than they could actually achieve. One patient reported "exercise is good for you up to a point." One GP had given consistent advice on exercise to his COPD patients and explained the reasons why it was OK to get out of breath as long as they did not feel out of control.

\section{Information on diet given by health professionals}

Many patients had been told to eat a 'healthy diet', to reduce cholesterol or to lose weight but none had been given detailed diet plans. Other patients when asked if they had been given dietary advice simply said "No". There was some confusion concerning the phrase 'healthy diet' in that many felt that the word 'diet' usually meant 'to lose weight'. There was also a belief that it was 'expensive to buy special food' and that diets tended to be 'complicated and boring'. In addition, recommendations to cut down on 'junk food' were insulting as they were from a generation that grew up without this type of food (often during the war and while rationing was still in place). The advice that would be relevant to patients with COPD concerning small, regular meals was only offered to one patient by their GP.

\section{Areas of interest and concern}

It was clear from the focus groups that COPD impacts on all aspects of patients' lives and severely restricts the ability 'to live a normal life'. For example one female patient described in detail how her shopping trips to town were carefully planned around the availability of public seating, as she needed to rest every hundred metres. Other patients remarked on the 'feeling of vulnerability' associated with their illness. In one poignant illustration a patient recalled an incident where during an exacerbation he had wanted to call his GP, but 
was unable to read the telephone number without his glasses, which he had left upstairs:

"Well they [the glasses] might as well have been in Outer Mongolia there was no way I could get up those stairs. Luckily I spotted my neighbour out the window and she came and helped out. But once that kind of thing happens it really accentuates one's vulnerability. It's like the fear of running out of these inhalers."

Other issues raised included patients' relationships with their doctors. Many patients felt that the GPs had no interest in them as patients and were unable to 'get past the receptionist' in some cases. Those few patients with a GP that remained supportive and approachable appreciated they were lucky; one such GP was recommended to others at one focus group. Many that had been referred to the Chest Clinic felt there was not enough contact with their Consultant to make much difference to their everyday lives. The patients who had access to a primary care respiratory nurse were unanimous in finding them reassuring and helpful.

\section{Discussion}

In contrast to asthma patients, COPD patients have chronic daily symptoms, incomplete relief from treatment and can expect progressive deterioration of their condition [11]. Many patients with COPD have frightening dyspnoea, feelings of panic during an exacerbation often with a spiral into depression and anxiety. This study suggests that intentional non-compliance with medication is low, probably because of their persistent symptoms and fear of exacerbations.

Many patients had confusing diagnoses, from asthma to chronic bronchitis; few had been given the name of their chest disease. The majority of patients had received poor quality information about lifestyle change and ongoing management with COPD. The advice that most patients were given about stopping smoking was not helpful-more practical help and support is needed.

Some of the advice to COPD patients byealth professionals was incorrect; for example, that exercise 'opens the lungs', or that getting breathless during exercise was 'bad for them'. The general feeling among COPD patients was that they needed to know what type of exercise is suitable for their disease and exactly 'how breathless' they could safely get.

Most patients were very unsure about what constituted a serious exacerbation and when to call for help. The general feeling of not wanting to 'bother the doctor' was evident in most of the COPD patients in the study and could cause delay in diagnosis, treatment and emergency care.

This study aimed to examine issues affecting compliance with recommended treatment in COPD patients and we found that patients reported their compliance with treatment to be good. However, we were surprised to observe the lack of information these patients had been given on their disease and management of their day-to-day lives. Most of the patients who responded to our invitation were keen to attend the focus group to find out more about their disease. They were interested to learn about new treatments, pulmonary rehabilitation and coping techniques for 'bad days'.

Previous research has highlighted poor implementation of practice guidelines for medication prescribing; [14] our findings indicate that this failure also extends to providing appropriate lifestyle advice. Compliance with drug medication appears to be good in COPD, but there is a poor understanding of the nature and treatment of COPD. As a result patients fail to make the critical lifestyle changes required to maintain their health, such as smoking cessation, exercise and diet. This research suggests that inadequacies of self-management in COPD patients are largely due to a lack of information. Further research is needed to examine quantitatively the proportion of patients who appear to be provided with inadequate information about lifestyle self-management and whether or not the way information is presented to patients affects their ability to recall that information [15].

\section{Acknowledgements}

This project was supported by a research grant from Boehringer Ingleheim. We would also like to thank Dr Emma Dellow for her help in the design of the study.

References

[1] Chmelik F, Doughty A. Objective measurements of compliance in asthma treatment. Annals of Allergy 1994;73:52732.

[2] Mawhinney H, Spector SL, Kinsman RA, et al. Compliance in clinical trials of two nonbronchodilator, antiasthma medications. Annals of Allergy 1991;66:294-8.

[3] Spector SL, Kinsman R, Mawhinney $\mathrm{H}$, et al. Compliance of patients with asthma with an experimental aerolized medication: Implications for controlled clinical trials. Journal of Allergy and Clinical Immunology 1986;77:6570 . 
[4] Bosley CM, Parry DT, Cochrane GM. Patient compliance with inhaled medication-does combining beta-agonists with corticosteroids improve compliance? European Respiratory Journal 1994;7:504-9.

[5] Apter AJ, Reisine ST, Affleck G, et al. Adherence with twice-daily dosing of inhaled steroids-Socioeconomic and health-belief differences. American Journal of Respiratory and Critical Care Medicine 1998;157:1810-7.

[6] Kleiger JH, Dirks JF. Medication compliance in chronic asthmatic patients. The Journal of Asthma Research 1979;16:93-6.

[7] van Es SM, LeCoq EM, Brouwer Al, et al. Adherence-related behaviour in adolescents with asthma: Results from focus group interviews. Journal of Asthma 1998;35:63746.

[8] Gallefoss F, Bakke PS. How does patient education and self-management among asthmatics and patients with chronic obstructive pulmonary disease affect medication? Am J Respir Crit Care Med 1999;160(6): 2000-5.
[9] Osman LM. How do patients' views about medication affect their self-management plans in asthma? Patient Education and Counselling 1997;32:S43-9.

[10] Fletcher C, Peto R. The natural history of chronic airflow obstruction. British Medical Journal 1977;1:1645-8.

[11] BTS standards of Care Subcommittee on Pulmonary Rehabilitation. Pulmonary Rehabilitation. Thorax 2001;56; 827-34.

[12] Hyland, ME. Rand CS. Compliance with asthma medicine. In: Bisgaard H, O'Callaghan C, Smaldone GC, editors. Drug delivery to the lung. (pp. 449-476) New York: Marcel Dekker; 2002.

[13] British Thoracic Society. Guidelines for the management of Chronic Obstructive Pulmonary Disease. Thorax 1997;52;S1-28.

[14] Ramsey SD. Suboptimal medical therapy in COPD. Chest 2000;117:33S-7S.

[15] Ley P, Bradshaw PW, Eaves D, Walker CM. A method for increasing patients' recall of information presented by doctors. Psychol Med 1973;3:217-20.

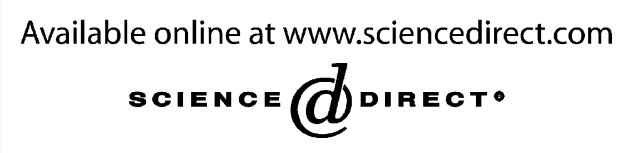

Available online at http://www.thepcrj.com

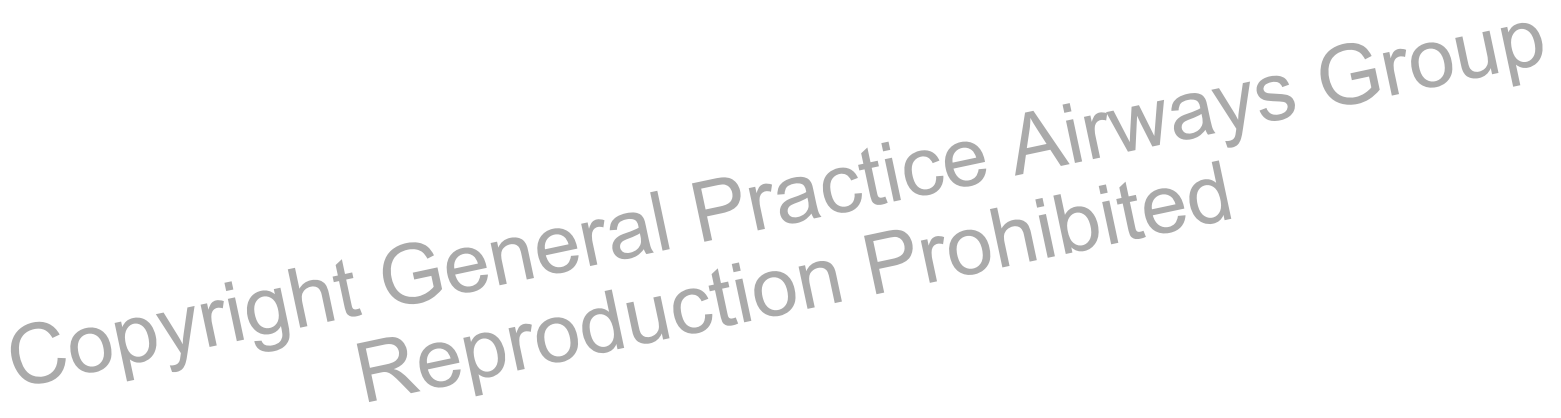

